\title{
The relationship between salivary cortisol concentrations and anxiety in adolescent and non-adolescent pregnant women
}

P.H.C. Rondó ${ }^{1}$, A.J. $\mathrm{Vaz}^{2}$, F. Moraes ${ }^{3}$ and A. Tomkins ${ }^{4}$

\author{
'Departamento de Nutrição, Faculdade de Saúde Pública, \\ 2Departamento de Análises Clínicas e Toxicológicas, \\ Faculdade de Ciências Farmacêuticas, and \\ ${ }^{3}$ Instituto de Matemática e Estatística, Universidade de São Paulo, \\ São Paulo, SP, Brasil \\ ${ }^{4}$ Centre for International Child Health, Institute of Child Health, \\ University of London, London, UK
}

\section{Correspondence \\ P.H.C. Rondó \\ Departamento de Nutrição \\ Faculdade de Saúde Pública, USP \\ Av. Dr. Arnaldo, 715 \\ 01246-904 São Paulo, SP \\ Brasil \\ Fax: +55-11-3066-7771 \\ E-mail:phcrondo@usp.br \\ Research supported by FAPESP (No. 1998/00321-0) and CNPq (No. 520/242/97-1). CAPES/British Council sponsored a link between University of São Paulo and University of London.}

Received October 16, 2003 Accepted May 18, 2004

\begin{abstract}
The main purpose of the present study was to determine the relationship between salivary cortisol concentrations and self-report anxiety in 50 adolescent and 178 non-adolescent women during the last month of pregnancy. The subjects were randomly selected from a previous study involving women who attended antenatal care from September 1997 to August 2000 at 17 health services in Southeast Brazil. Salivary cortisol was measured with an enzyme immunoassay kit, and anxiety was assessed by the State-Trait Anxiety Inventories (STAI) of Spielberger. After saliva collection, the participants completed the STAI. Mean concentrations of cortisol for both pregnant adolescents $(14.17 \pm 6.78 \mathrm{nmol} / \mathrm{l})$ and non-adolescents $(13.81 \pm 8.51 \mathrm{nmol} / \mathrm{l})$ were similar $(\mathrm{P}=0.89)$. Forty-three percent of the pregnant adolescents and $30.5 \%$ of the non-adolescents felt anxious at the time of being questioned (State Anxiety Inventory (SAI) scores $>40 ; \mathrm{P}=0.06$ ). Cortisol concentrations in adolescents were negatively related to the SAI scores $(r=-0.39 ; \mathrm{P}=0.01)$ which assess a temporary condition of anxiety. There was a statistically significant difference in mean cortisol concentrations between adolescents with low $(\leq 40)$ and high $(>40)$ SAI scores $(\mathrm{P}=0.03, t$-test $)$, but no differences for non-adolescents. The negative relationship between salivary cortisol concentrations and anxiety scores in adolescents may be due to puberty-related hormone differences during this period of life. Pregnant adolescents may possess unique biological or psychological characteristics compared to adults and non-pregnant adolescents. Thus, we need to know more about the hypothalamic-pituitary-adrenocortical axis of pregnant adolescents.
\end{abstract}

Key words - Anxiety - Salivary cortisol - Pregnant adolescents - State Anxiety Inventory 


\section{Introduction}

Cortisol peaks in late pregnancy as a result of placental production of corticotrophin-releasing hormone (CRH) and falls abruptly at delivery. It seems that the increased free and total cortisol levels in pregnancy are related to resetting of the sensitivity of the hypothalamic-pituitary-adrenal (HPA) axis and not merely to an increase in corticotrophin-binding globulin or $\mathrm{CRH}$ levels (1).

During pregnancy, cortisol may influence placental function, uterine blood flow, and uterine irritability, indirectly controlling the growth and development of the fetus or the onset of preterm labor (2).

According to Kirschbaum and Hellhammer (3), measurement of cortisol in saliva has become a valuable alternative due to the non-invasiveness and laboratory independence of sampling. Cortisol levels in saliva are not affected by saliva flow rate since the hormone probably enters saliva by passive diffusion. In addition, the acinar cells lining the saliva glands prevent proteins and protein-bound molecules from entering saliva. Thus, salivary cortisol determination is a simple measure of the unbound "free" hormone fraction and has a number of potential advantages over the more conventionally used total serum concentrations. These advantages include a stress-free and non-invasive collection procedure and the measurement of a parameter which is believed to reflect the serum concentration of biologically active unbound cortisol.

In recent years, psychological factors such as anxiety have been increasingly linked to hormonal alterations in the body such as cortisol secretion. The psychological status of an individual, per se, is an effective stimulus for the activation of the adrenal system, which can be demonstrated by saliva cortisol measurement (4). The importance of assessing cortisol levels and self-report anxiety in pregnant adolescents is that both adoles- cence and pregnancy are periods of development characterized by hormonal and emotional changes (5). According to some studies, anxiety and/or depression are particularly more prevalent among pregnant adolescents (6-8).

Therefore, the purpose of this investigation was to examine: 1) the relationship between the concentrations of salivary cortisol and self-report anxiety of adolescent and non-adolescent pregnant women and 2) the prevalence of self-report anxiety in pregnancy.

\section{Material and Methods}

A total of 228 pregnant women were recruited from a longitudinal cohort study carried out between 1997 and 2000 at 15 health units and 2 hospitals in Jundiaí, SP, Brazil (8), for anxiety assessment. Women with chronic infectious diseases, metabolic diseases, cardiopathy, mental diseases, hypertension/pre-eclampsia/eclampsia and multiple deliveries were not included in the study.

Self-report anxiety was determined by the State-Trait Anxiety Inventories (STAI) (9) and by saliva cortisol measurements. The STAI offers a reliable and widely used measure of anxiety. By providing a measure of state and trait anxiety, the STAI is the best suited instrument for establishing baseline levels of anxiety in pregnant women (10). It is a well-standardized, 40-item, self-report instrument designed to measure both state and trait anxiety. For the State Anxiety Inventory (SAI), subjects are asked how they feel at the time of being questioned, and for the Trait Anxiety Inventory (TAI), subjects are asked how they feel generally. A cut-off point of scores $>40$ was selected for both SAI and TAI. After saliva collection, the participants completed the STAI. Salivary cortisol concentrations were measured as an indicator of the activation of the HPA axis because the biological activity of steroid 
hormones is a function of the free (nonprotein-bound) portion of total hormone levels. Researchers have demonstrated that salivary cortisol concentrations accurately reflect free plasma cortisol levels, even as total cortisol levels rise throughout pregnancy (11). Therefore, saliva cortisol in pregnancy is a sensitive index of anxiety during this period.

Women were assessed at home by field workers and instructed to rinse their mouth with water before collection of the saliva samples into "salivette" tubes (Sarstedt Inc., Nümbrecht, Germany). The "salivette" assembly mainly consists of a small cotton swab which fits inside a standard centrifugation tube. By gently chewing on the swab, subjects stimulate saliva flow to a rate that provides sufficient material within 30-60 s. Not only does saliva sampling with the "salivette" avoid emotive biases toward the specimen, but it also facilitates pipetting of the sample since the debris is separated from the clear watery saliva supernatant (3). Three saliva samples were obtained between 8:30 and 9:00 am to control for diurnal variations in hormonal concentrations. The samples were kept on ice, centrifuged, and stored at $-20^{\circ} \mathrm{C}$ for a maximum of a month, until assayed. Cortisol was measured with a salivary cortisol enzyme immunoassay kit (Salimetrics, LLC, State College, PA, USA) in the Department of Clinical and Toxicological Analyses, Faculty of Pharmaceutical Sciences, University of São Paulo. All women were assessed during late pregnancy (mean gestational age in weeks $=35.97 ; \mathrm{SD}=4.84$ ).

Spearman correlations were used to determine the relations between salivary cortisol and anxiety scores in adolescent and nonadolescent pregnant women, and the consistency of the relations. The level of significance was set at $\mathrm{P} \leq 0.05$. Data were analyzed statistically using SPSS for Windows, Version 10 (1999) and Statistic (StatSoft, Inc., 1995) software.

The study was approved by the Ethics Committee of the University of São Paulo and the Secretary of Health of Jundiaí city, where the data were collected. Written informed consent was obtained from the women.

\section{Results}

The characteristics of the pregnant women included in the study are specified in Table 1. Adolescents had a lower per capita income than non-adolescents $\left(\lambda^{2}=12.08 ; \mathrm{P}=\right.$ $0.002)$. Most of the adolescents were single (without a partner) and primiparous, compared to non-adolescents $\left(\lambda^{2}=32.16 ; \mathrm{P}<\right.$ 0.001 ).

Means and standard deviations for the salivary cortisol concentrations and the STAI scores are shown in Table 2. Mean cortisol

Table 1. Characteristics of adolescent and non-adolescent pregnant women who participated in the present study.

\begin{tabular}{|c|c|c|}
\hline Characteristics & Adolescents $(N=50)$ & Non-adolescents $(N=178)$ \\
\hline \multicolumn{3}{|l|}{ Age (years) } \\
\hline $13-16$ & 23.5 & - \\
\hline $17-19$ & 76.5 & - \\
\hline $20-29$ & - & 72.3 \\
\hline $30-42$ & - & 27.7 \\
\hline \multicolumn{3}{|l|}{ Education (years) } \\
\hline$\leq 4$ & 11.8 & 18.6 \\
\hline $5-8$ & 33.3 & 37.9 \\
\hline$>8$ & 54.9 & 43.5 \\
\hline \multicolumn{3}{|l|}{ Per capita income in MMBW } \\
\hline$<1$ & 33.3 & 14.8 \\
\hline $1-3$ & 54.9 & 55.7 \\
\hline$>3$ & 11.8 & 29.5 \\
\hline \multicolumn{3}{|l|}{ Marital status } \\
\hline Married & 23.50 & 65.0 \\
\hline Single (with a partner) & 19.70 & 19.6 \\
\hline Single (without a partner) & 52.90 & 17.5 \\
\hline Divorced & 3.90 & 2.9 \\
\hline \multicolumn{3}{|l|}{ Parity } \\
\hline 0 & 86.3 & 41.2 \\
\hline $1-4$ & 13.7 & 58.2 \\
\hline$\geq 5$ & - & 0.6 \\
\hline \multicolumn{3}{|l|}{ Cigarette smoking } \\
\hline Yes & 5.9 & 8.5 \\
\hline No & 94.1 & 91.5 \\
\hline \multicolumn{3}{|l|}{ Alcohol consumption } \\
\hline Yes & 11.8 & 12.4 \\
\hline No & 88.2 & 87.6 \\
\hline
\end{tabular}

Data are reported as percent. MMBW = minimum monthly Brazilian wage (US\$55.00). 
Table 2. Salivary cortisol concentrations and anxiety scores for adolescent and non-adolescent pregnant women.

\begin{tabular}{lcc}
\hline & $\begin{array}{c}\text { Adolescents } \\
(\mathrm{N}=50)\end{array}$ & $\begin{array}{c}\text { Non-adolescents } \\
(\mathrm{N}=178)\end{array}$ \\
\hline Cortisol & $14.17 \pm 6.78$ & $13.81 \pm 8.51^{\mathrm{ns}}$ \\
SAl & $39.68 \pm 9.52$ & $37.04 \pm 7.96^{\mathrm{ns}}$ \\
TAl & $43.96 \pm 9.94$ & $40.5 \pm 10.25^{*}$ \\
\hline
\end{tabular}

Data are reported as means \pm SD of cortisol concentration in $\mathrm{nmol} / \mathrm{l}$. SAI = State Anxiety Inventory; TAI = Trait Anxiety Inventory (Ref. 9).

${ }^{*} P=0.042$, ns $P>0.05$ compared to adolescents (Student $t$-test).
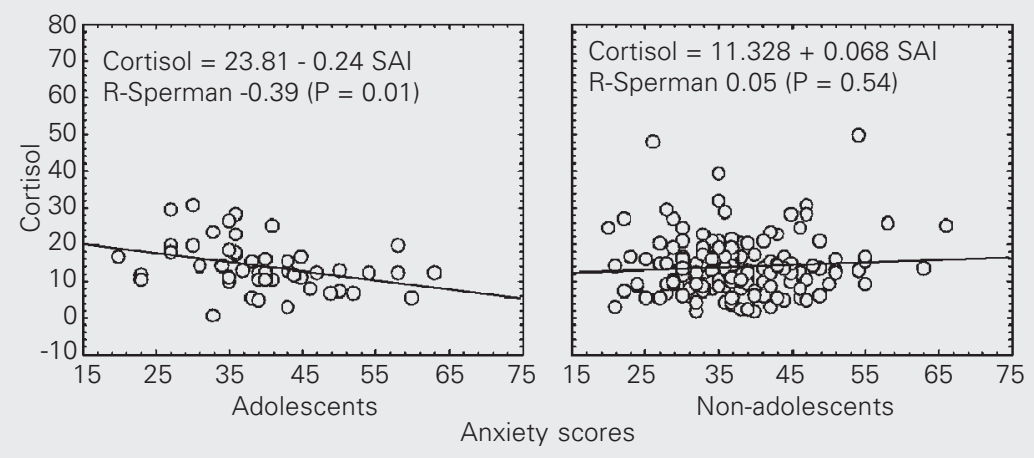

Figure 1. Regression analysis of salivary cortisol versus anxiety scores for adolescent ( $\mathrm{N}=$ 50 ) and non-adolescent $(N=178)$ pregnant women. Anxiety scores were obtained by application of the State Anxiety Inventory (SAI, Ref. 9).

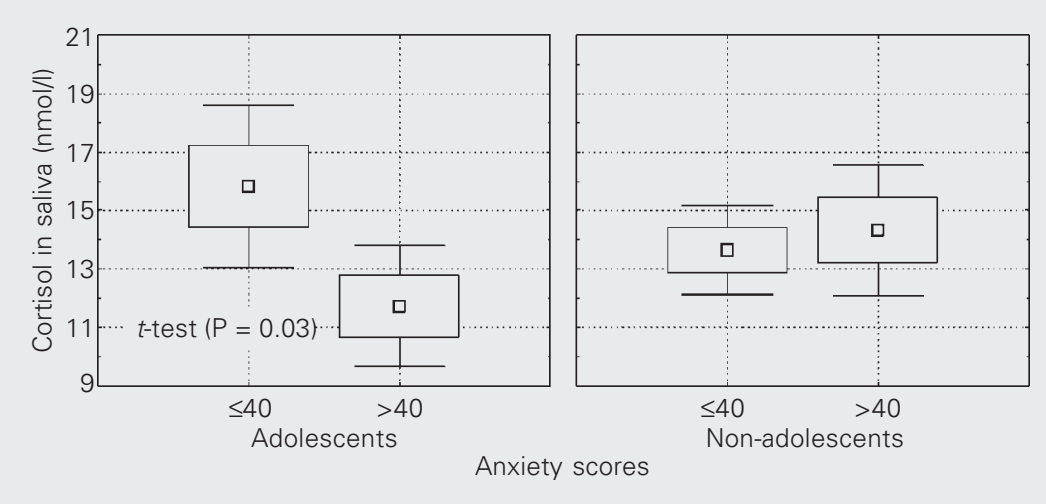

Figure 2. Comparison of mean salivary cortisol with low $(\leq 40)$ and high $(>40)$ anxiety scores in adolescent $(N=50)$ and non-adolescent $(N=178)$ pregnant women. The square in the center of the box plot corresponds to the mean. The horizontal lines of the box correspond to the 25th and 75th percentiles and the bars to the maximum and minimum values. Anxiety scores were obtained by application of the State Anxiety Inventory (Ref. 9). concentrations were similar $(\mathrm{P}=0.89)$ for pregnant adolescents and non-adolescents, and lower $(12,13)$ or similar $(1,14-16)$ to those reported in other studies. Mean TAI scores for both groups of women were higher than the cut-off point ( $>40)$ used to classify individuals as being generally anxious. Adolescents showed higher mean TAI scores compared to non-adolescents $(\mathrm{P}=0.04)$. Forty-three percent of the pregnant adolescents and $30.5 \%$ of the non-adolescents felt anxious at the time of being questioned (SAI scores $>40 ; \mathrm{P}=0.06)$. Approximately $63 \%$ of the pregnant adolescents and $51.4 \%$ of the non-adolescents felt generally anxious (TAI scores $>40 ; \mathrm{P}=0.10$ ).

Spearman correlation coefficients between salivary cortisol concentrations and SAI scores for pregnant adolescents and nonadolescents are shown in Figure 1. Cortisol concentrations were negatively correlated with the SAI scores in adolescents $(r=-0.39$; $\mathrm{P}=0.01)$. There was a statistically significant difference $(\mathrm{P}=0.03, t$-test $)$ in mean salivary cortisol concentrations between adolescents with low $(\leq 40)$ and high $(>40)$ SAI scores (Figure 2).

\section{Discussion}

As far as we know, this is the only epidemiological study in the literature comparing self-report anxiety assessed by the STAI and cortisol concentrations of adolescent and nonadolescent pregnant women. Our results agree with other studies involving pregnant adolescents, showing a negative association between low cortisol concentrations and symptoms of anxiety, depression, or conduct disorder $(5,17)$.

Individuals with high HPA axis reactivity tend to have more significant distress (anxiety, depression, etc.) symptoms, and higher cortisol concentrations (18). However, the association between high cortisol concentrations and distress has come mainly from studies of more severely or chronically 
distressed subjects (19-21), and does not seem to be significant in healthy adults $(22,23)$. Cortisol concentrations are high not only in severely or chronically distressed adults, but also in pregnant women (2,2426). Nevertheless, it should be emphasized that the high concentrations of cortisol in pregnancy are not pathological.

In contrast to data obtained for distressed adults, lower concentrations of cortisol and $\mathrm{CRH}$ were associated with depression and conduct disorder symptoms in pregnant adolescents $(5,17)$, indicating a pattern of hyporesponsiveness of the HPA axis in these women. Ponirakis et al. (12) reported that pregnant adolescents with higher negative TAI scores and lower salivary cortisol concentrations had more positive birth outcomes. The HPA axis reactivity in the non-hypothesized direction in pregnant adolescents does have some explanations. The neuroendocrine changes unique to pregnancy in adolescence may account in part for this finding, considering the puberty-related hormone changes during this period of life. Gonadal steroid concentrations are still increasing in adolescents after menarche (27). Therefore, adolescents are in a period of life during which rapid biological and even psychosocial development occurs. The less mature hypothalamic-pituitary-gonadal axis in adolescence, along with the many hormonal changes in pregnancy, may interact with the HPA axis or with psychological factors in some unknown way, producing emotional changes in pregnant adolescents (5). Another explanation is that the high $\mathrm{CRH}$ and cortisol concentrations reported in depressed adults may be interpreted as a result of attempts at homeostasis following repeated depressive symptoms (17). Although adolescence is a distressful period for some women $(6,8,28)$, adolescents experience a relatively shorter history of distress compared to adults, and probably the distressrelated alterations in HPA feedback systems have not yet become established (17). Thus, low cortisol may be a physiological correlate of depression and anxiety during pregnancy in adolescence.

In the few studies of the HPA axis in adolescents (non-pregnant) with depression (7,29-32), it seems that there are few consistent HPA axis changes comparable to adults with depression (e.g., hypercortisolism). In a study carried out by Dorn et al. (33), depressed adolescents did not show the predictable ACTH and cortisol response to an ovine CRH challenge test. Non-suppression of cortisol secretion during the "dexamethasone suppression test", a marker of some types of adult depression, was shown to be unreliable and non-specific in children and adolescents $(34,35)$.

While cortisol levels are known to increase significantly in pregnant women, the exact role of these higher levels is not fully understood. A study involving mainly adult pregnant women reported little association between psychological scores and cortisol concentrations (36). Smith et al. (37) did not find significant correlations between cortisol levels and mood disturbances in a study involving adult and adolescent primiparous women. Smith and Thomson (38) reported that during pregnancy the HPA axis shows loss of the normal suppression of cortisol by dexamethasone, and elevated basal levels of cortisol with preservation of a diurnal rhythm, features also found in patients with endogenous depression. It is possible that the unique physiological and psychological changes of pregnancy lead to different relations between cortisol levels and self-report anxiety than those observed in non-pregnant individuals. We agree with McCool et al. (11) and Dorn and Susman (5) when they emphasize the need to know more about the physiology of pregnancy, in particular the HPA axis, and whether the physiology of pregnancy in adolescence is different from that in adults.

Therefore, future larger epidemiological studies should be conducted to investigate hormonal concentrations and anxiety/depres- 
sion in pregnant and non-pregnant adults and adolescents and to examine the influences of age, development and gestational status on their HPA axis.

\section{Acknowledgments}

The authors gratefully acknowledge the
Secretary of Health of Jundiaí city and the staff of Hospital Maternidade de Jundiaí, Hospital de Caridade São Vicente de Paulo, Hospital Dr. Paulo Sacramento, Hospital Santa Rita de Cássia, Casa de Saúde Dr. Domingos Anastácio, and Centro Médico Pitangueiras, for permitting us to carry out our study in their Services.

\section{References}

1. Scott EM, McGarrigle HHG \& Lachelin GCL (1990). The increase in plasma and saliva cortisol levels in pregnancy is not due to the increase in corticosteroid-binding globulin levels. Journal of Clinical Endocrinology and Metabolism, 71: 639-644.

2. McLean M \& Smith R (1999). Corticotropin-releasing hormone in human pregnancy and parturition. Trends in Endocrinology and Metabolism, 10: 174-178.

3. Kirschbaum C \& Hellhammer DH (1994). Salivary cortisol in psychoneuroendocrine research: recent developments and applications. Psychoneuroendocrinology, 19: 313-333.

4. Kirschbaum C \& Hellhammer DH (1989). Salivary cortisol in psychobiological research: an overview. Neuropsychobiology, 22: 150-169.

5. Dorn LD \& Susman EJ (1993). Serum and saliva cortisol relations in adolescents during pregnancy and the early postpartum period. Biological Psychiatry, 34: 226-233.

6. Petersen AC, Compas BE, Brooks-Gunn J, Stemmler M, Ey S \& Grant KE (1993). Depression in adolescence. American Psychologist, 48: 155-168.

7. Susman EJ, Dorn LD, Inoff-Germain G, Nottelmann ED \& Chrousos GP (1997). Cortisol reactivity, distress behavior, behavior problems, and emotionality in young adolescents: a longitudinal perspective. Journal of Research on Adolescence, 7: 81-105.

8. Rondó PHC, Ferreira RF, Nogueira F, Ribeiro MCN, Lobert H \& Artes $R$ (2003). Maternal psychological stress and distress as predictors of low birth weight, prematurity and intrauterine growth retardation. European Journal of Clinical Nutrition, 57: 266-272.

9. Spielberger CD, Gorsuch RL \& Lushene RE (1983). Manual for the State-Trait Anxiety Inventory. Consulting Psychologist Press, Palo Alto, CA, USA

10. Ayers $S$ (2001). Assessing psychopathology in pregnancy and postpartum. Journal of Psychosomatic Obstetrics and Gynaecology, 22: 91-102.

11. McCool WF, Lorah DD \& Susman EJ (1994). The relation of cortisol reactivity and anxiety to perinatal outcome in primiparous adolescents. Research in Nursing and Health, 17: 411-420.

12. Ponirakis A, Susman EJ \& Stifer CA (1998). Negative emotionality and cortisol during adolescent pregnancy and its effects on infant health and autonomic nervous system reactivity. Developmental Psychobiology, 33: 163-174.

13. Sikkema JM, Robles de Medina PG, Schaad RR, Mulder EJ, Bruinse HW, Buitelaar JK, Visser GH \& Franx A (2001). Salivary cortisol levels and anxiety are not increased in women destined to develop preeclampsia. Journal of Psychosomatic Research, 50: 45-49.

14. Darne FJ, McGarrigle HHG \& Lachelin CL (1989). Diurnal variation of plasma and saliva oestrogen, progesterone, cortisol and plasma dehydroepiandrosterone sulphate in late pregnancy. European Journal of Obstetrics, Gynecology, and Reproductive Biology, 32: 57-66.

15. Allolio B, Hoffmann J, Linton EA, Winkelmann W, Kusche M \& Schulte HM (1990). Diurnal salivary cortisol patterns during pregnancy and after delivery: relationship to plasma corticotrophin-releasing hormone. Clinical Endocrinology, 33: 279-289.

16. McCool WF \& Susman EJ (1994). Cortisol reactivity and self-report anxiety in the antepartum: predictors of maternal intrapartal outcomes in gravid adolescents. Journal of Psychosomatic Obstetrics and Gynaecology, 15: 9-18.

17. Susman EJ, Schmeelk KH, Worrall BK, Granger DA, Ponirakis A \& Chrousos GP (1999). Corticotropin-releasing hormone and cortisol: longitudinal associations with depression and antisocial behavior in pregnant adolescents. Journal of the American Academy of Child and Adolescent Psychiatry, 38: 460-467.

18. Van Eck M, Berkhof H, Nicolson N \& Sulon J (1996). The effects of perceived stress, traits, mood states, and stressful daily events on salivary cortisol. Psychosomatic Medicine, 58: 447-458.

19. Rahe RH, Karson S, Howard Jr NS, Rubin RT \& Poland RE (1990). Psychological and physiological assessments on American hostages freed from captivity in Iran. Psychosomatic Medicine, 52: 116.

20. Aronsson G \& Rissler A (1998). Psychophysiological stress reactions in female and male urban bus drivers. Journal of Occupational Health Psychology, 3: 122-129.

21. Grossi G, Perski A, Lundberg U \& Soares J (2001). Associations between financial strain and the diurnal salivary cortisol secretion of long-term unemployed individuals. Integrative Physiological and Behavioral Science, 36: 205-219.

22. Brandtstädter J, Baltes-Götz B, Kirschbaum C \& Hellhammer D (1991). Developmental and personality correlates of adrenocortical activity as indexed by salivary cortisol: Observations in the age range of 35-65 years. Journal of Psychosomatic Research, 35: 173185.

23. Zorrilla EP, DeRubeis RJ \& Redei E (1995). High self-esteem, hardiness and affective stability are associated with higher basal pituitary-adrenal hormone levels. Psychoneuroendocrinology, 20: 591601.

24. Carr BR, Parker CRJ, Madden JD, McDonald PC \& Porter JC (1981). Maternal plasma adrenocorticotropin and cortisol relationships throughout human pregnancy. American Journal of Obstetrics and Gynecology, 139: 416-422.

25. Linton EA, Wolfe CDA \& Lowry PJ (1991). Placental corticotrophin- 
releasing hormone: activator of the pituitary adrenal-axis in human pregnancy? Proceedings of the Nutrition Society, 50: 363-370.

26. Goland RS, Conwell IM, Warren WB \& Wardlaw SL (1992). Placental corticotropin-releasing hormone and pituitary-adrenal function during pregnancy. Neuroendocrinology, 56: 742-749.

27. Lemarchand-Beraud T, Zufferey MM, Reymond M \& Rey I (1982). Maturation of the hypothalamo-pituitary-ovarian axis in adolescent girls. Journal of Clinical Endocrinology and Metabolism, 54: 241246.

28. Jacobson L, Churchill R, Donovan C, Garralda E \& Fay J (2002). Tackling teenage turmoil: primary care recognition and management of mental ill health during adolescence. Family Practice, 19: 401-409.

29. Klee SH \& Garfinkel BD (1984). Identification of depression in children and adolescents: the role of the dexamethasone suppression test. Journal of the American Academy of Child and Adolescent Psychiatry, 23: 410-415.

30. Puig-Antich J (1987). Sleep and neuroendocrine correlates of affective illness in childhood and adolescence. Journal of Adolescent Health Care, 8: 505-529.

31. Dahl RE, Ryan ND, Puig-Antich J, Nguyen NA, al-Shabbout M, Meyer VA \& Perel J (1991). 24-hr cortisol measures in adolescents with major depression: a controlled study. Biological Psychiatry, 30: 25-36.

32. Martel FL, Hayward C, Lyons DM, Sanborn K, Varady S \& Schatzberg AF (1999). Salivary cortisol levels in socially phobic adolescent girls.
Depression and Anxiety, 10: 25-27

33. Dorn LD, Burgess ES, Susman EJ, von Eye A, De Bellis MD \& Gold PW (1996). Response to $\mathrm{OCRH}$ in depressed and nondepressed adolescents: does gender make a difference? Journal of the American Academy of Child and Adolescent Psychiatry, 35: 764-773.

34. Doherty MB, Mandansky D, Kraft J, Carterake LL, Rosenthal PA \& Coughlin BF (1986). Cortisol dynamics and test performance of the dexamethasone suppression test in 97 psychiatrically hospitalized children aged 3-16 years. Journal of the American Academy of Child and Adolescent Psychiatry, 25: 400-408.

35. Dahl RE, Kaufman J, Ryan ND, Perel J, al-Shabbout M, Birmaher B, Nelson B \& Puig-Antich J (1992). The dexamethasone suppression test in children and adolescents: a review and controlled study. Biological Psychiatry, 32: 109-126.

36. Milad MP, Klock SC, Moses S \& Chatterton R (1998). Stress and anxiety do not result in pregnancy wastage. Human Reproduction, 13: 2296-2300.

37. Smith R, Cubis J, Brinsmead M, Lewin T, Singh B, Owens P, Chan EC, Hall C, Adler R \& Lovelock M (1990). Mood changes, obstetric experience and alterations in plasma cortisol, beta-endorphin and corticotrophin releasing hormone during pregnancy and the puerperium. Journal of Psychosomatic Research, 34: 53-69.

38. Smith R \& Thomson M (1991). Neuroendocrinology of the hypothalamo-pituitary-adrenal axis in pregnancy and the puerperium. Baillieres Clinical Endocrinology and Metabolism, 5: 167-186. 